\title{
The question of life, the universe and event attribution
}

\author{
Weather and climate service providers around the world are looking to issue assessments of the human role in \\ recent extreme weather events. For this attribution to be of value, it is important that vulnerability is acknowledged \\ and questions are framed appropriately.
}

\section{Dáithí A. Stone, Suzanne M. Rosier and David J. Frame}

vent attribution, the study of the anthropogenic influence on individual extreme weather events, has been around for about 15 years. Interest in the role of increasing greenhouse gas emissions on extreme weather has existed much longer, but relating emissions to one-off events was only posed in 2003 (ref. ${ }^{1}$ ) in the investigation of a summer heatwave that hit France, Italy, Switzerland and neighbouring areas during August 2003. That summer was the hottest at that time since $1500 \mathrm{AD}$, and the study concluded that anthropogenic emissions at least doubled the risk of heat at that magnitude ${ }^{2}$. Now, weather and climate service providers endeavour to issue these assessments in real time ${ }^{3}$.

The heat-related human mortality in early August was what motivated the authors of the European heatwave study ${ }^{2}$. Yet they wanted to avoid a selection bias from specifying event conditions too closely matched to those that actually occurred. Their solution was to adopt an event definition that was in frequent use within the research community at the time, examining average June-August temperature over a large region including North Africa, the Middle East and Europe. More recent investigations have found that these choices affected the determined anthropogenic contribution to the risk of temperature threshold exceedance, and therefore the study's relevance to the mortality outcome ${ }^{4,5}$. While mortality was the motivation for the study, that vulnerability was ignored in the analysis.

As event attribution has matured, issues with event definition and choices made during attribution analysis have become evident. Some studies have examined the same event using different methods, with the result that many qualitative conclusions are seemingly not replicable ${ }^{6}$. This discrepancy is due in part to the probabilistic nature of climate analysis and different data sources; for examples, see refs. ${ }^{7-9}$. But it is also due to the lack of a common standard for when 'negligible influence' transitions to 'substantial influence's. Nuances in event definitions and differences in the research question are also involved ${ }^{10,11}$.

\section{Framing and conditioning}

A well-documented example of the importance of the research question involves analysis of the 2010 July heatwave over western Russia. One study concluded that the role of human interference was negligible ${ }^{12}$, while another concluded that it was dominant ${ }^{13}$. Otto et al. ${ }^{14}$ noted these two studies were asking different questions, and that technically the results were consistent.

We illustrate the difference with a schematic. Consider the effect of a local $2.0^{\circ} \mathrm{C}$ warming with variability unaffected, shown by two temperature probability distributions, identical except one is shifted to the right by $2.0^{\circ} \mathrm{C}$ (Fig. 1 ). If vulnerability is defined by a 95 th percentile (or 1-in-20) event, that event would be 7.1 ${ }^{\circ} \mathrm{C}$ in the cooler climate but $9.1^{\circ} \mathrm{C}$ in the warmer world. Viewed in this way, a $7.1^{\circ} \mathrm{C}$ fluctuation from the average temperature is the main factor behind the event's magnitude, not the $2.0^{\circ} \mathrm{C}$ shift. Similarly, the approach of Dole et al. ${ }^{12}$, which found negligible influence for the 2010 event, would note that a 1 -in-20 event $\left(\right.$ a $7.1^{\circ} \mathrm{C}$ 'extreme' in the cooler climate) is $2.0^{\circ} \mathrm{C}$ warmer in the warmer climate, which is small compared to the anomalous $7.1^{\circ} \mathrm{C}$ magnitude of the event: the climate warming was not important to the nature of the event.

However, the situation differs when considering the occurrence of the event. If the vulnerability is instead defined as exceeding a temperature that is $7.1^{\circ} \mathrm{C}$ above average in the cooler climate, it will be easier to exceed that temperature in the warmer world. In this case, the additional $2^{\circ} \mathrm{C}$ of warming more than doubles the probability of reaching or exceeding that threshold, making it a 1-in-10 event. The approach of Rahmstorf and Coumou ${ }^{13}$, which found dominant human influence in 2010, would

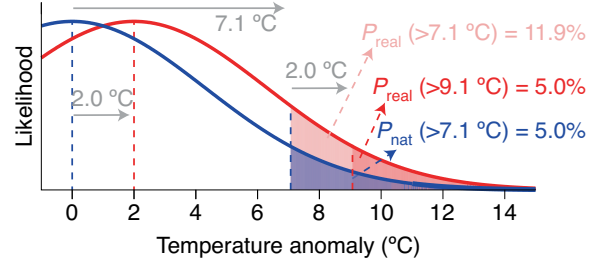

Fig. 1 | Schematic to illustrate different framing options for event attribution studies. Two probability distributions represent the climate under cooler ('natural world') conditions and warmer ('real world') conditions, with the

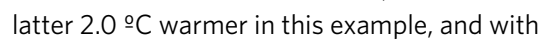
the variability (shape) of the distributions unchanged. $P_{\text {real }}(>x)$, the probability of exceeding a threshold $x$ under warmer conditions; $P_{\text {nat }}(>x)$, the probability of exceeding a threshold $x$ under cooler conditions.

note that the shift in the distribution more than doubles the probability of meeting or exceeding that 1-in-20 threshold: the climate shift was the most important contributor to the event's occurrence.

Differences in questions asked are usually referred to as 'framing, while differences in how questions are addressed are referred to as 'conditioning' ${ }^{3,15,16}$. Current guidance stipulates that these should be articulated


has also been suggested that framing selection should be considered a source of uncertainty ${ }^{3,8,17}$. However, there may be very good reasons for asking a specific question. For instance, an insurer of a bridge over a river will want to know how likely a damaging flood is during the upcoming period of cover. By contrast, an engineer upgrading the bridge will want to know how much to raise it in response to changes to the design $n$ year flood height. This is the same difference noted by Otto et al. ${ }^{14}$ between the western Russian studies. So, whether human influence on extreme weather is hazardous for the bridge may depend strongly on whether an insurer or an 
Box 1 | Main challenges in the development of operational event attribution services

Identification of vulnerabilities: what are the relevant vulnerabilities motivating operational services? At present, a major motivation for real-time services is to provide input to the news cycle ${ }^{3,31,32}$. What, if any, are the vulnerabilities identified by the news cycle? These will inevitably vary across regions and cultures ${ }^{33}$, and are likely to be multivariate functions of the weather state.

Diversity of vulnerabilities: how should operational services proceed when multiple vulnerabilities are identified, such as when human health and economic costs have different sensitivity thresholds? Both proactive and reactive services could perform multiple investigations directed by a variety of vulnerabilities. However, if conclusions differ across those investigations, how can they be accurately represented in soundbites?

Omission of vulnerabilities: should, or how should, unrepresented vulnerabilities be treated? The news focus might be on mortality, but a particular community may be more concerned about the crops they grow, and their profitability and viability. How, and under what conditions, can important but unrepresented vulnerabilities be reflected in operational services at low cost? How can communities

engineer is asking. This is not uncertainty, at least not classically so.

\section{Question dependence}

Question dependence can still be important when differences between questions are subtle. For example, in the above case, we assumed that the $7.1^{\circ} \mathrm{C}$ threshold is equally relevant in both climates. But suppose instead that we are interested in exceedance of a threshold at which either tortoises or fruit flies experience harm. For tortoises, that might be a fixed threshold independent of recent climate change $\left(7.1^{\circ} \mathrm{C}\right.$ in Fig. 1$)$. But for fruit flies, with short lifespans and high evolutionary adaptive capacity, the threshold in a world without climate change may not be relevant for the anthropogenic scenario: they may have adapted to a climate representative of only a decade or so ago (a little less than the red $9.1^{\circ} \mathrm{C}$ in Fig. 1). The thresholds relevant for the two scenarios may then differ by nearly as much as centennial-scale climate change. So, in this case, the conclusion of the anthropogenic role in a weather event depends on whether the focus is on tortoises or fruit be informed when their concerns have not been addressed, and how can service providers be made aware that they are missing important vulnerabilities? This challenge is likely to have a strong socioeconomic component to it, given the propensity for the most vulnerable groups in societies to be among those with the weakest institutional voices.

Transience of vulnerabilities: how should an operational service deal with a shifting focus of vulnerabilities throughout an event? The most intense natural disasters disrupt monitoring networks, so sometimes the relevant magnitudes of impacts are not understood until well after the event. For the news, this may mean that a question concerning the vulnerability of infrastructure is superseded by a question concerning the vulnerability of human lives (say, after the landfall of a hurricane), which may result in a different analysis and conclusion. Proactive services may lack the flexibility to switch questions; if reactive services switch in order to remain relevant, do they remain credible in the eyes of the audience, given that the numbers, and possibly the substantive conclusions regarding anthropogenic influence, may appear to change?

flies, which is irrelevant to anthropogenic interference with the climate system or the magnitude-versus-probability framing philosophy in Fig. 1.

Therefore, the solution may be to simply ask one question, answer it and ignore that another question could be asked $^{18,19}$. However, this would likely lead to confusion or disagreement with the realization that a different question could be posed. Alternatively, one could ask all the appropriate questions and take the range of answers as uncertainty ${ }^{8,17}$, although this would hide potentially useful information in a lot of noise. The problem is that, in both instances, the analysis is incomplete.

\section{Vulnerability-centred attribution}

Until now, event attribution has quantified the human influence on the climate system, yet it is becoming clear that event attribution also needs to consider vulnerabilities. From this vulnerability-centred perspective, articulating the framing alone is insufficient. Rather than concluding 'the event was $x$ times more likely because of our emissions' (or ' $y$ larger in magnitude'), a more appropriate statement might be 'the vulnerability $v$ was exposed to a hazard $h$ that was $x$ times more likely because of anthropogenic emissions' (or ' $y$ larger'). For example, 'the bridge was exposed to a flood that was twice as likely because of anthropogenic emissions'.

There are recent efforts to merge extreme weather event attribution with the analysis of extremes in non-climate systems (like public health or infrastructure $)^{20-23}$, but our call for clarity on vulnerability is distinct. In those analyses, the various risk factors of the non-climate event need to be compared $^{24}$. For example, the high mortality seen in August 2003 in France arose from a combination of trends in demographics, behaviour, preparedness of health services and medical technology, as well from the anthropogenic warming ${ }^{20,23,25}$. These investigations are not extreme weather attribution studies, however, and so they are beyond the scope of this piece.

This raises a number of challenges for the burgeoning service of operational event attribution, wherein analyses are carried out as soon as events occur. There are two broad types. Reactive services are triggered by the occurrence of an extreme event ${ }^{26-28}$, while proactive services perform and circulate analyses systematically for a class of events in advance, regardless of whether they occur $^{29,30}$. Reactive services are topical and flexible, but also strongly subject to selection bias; proactive services strive to minimize selection bias but at the cost of topicality and specificity ${ }^{3}$. We identify four main challenges in the development of operational event attribution services regarding how vulnerability maps to event attribution: identification, diversity, omission and transience (Box 1).

To some extent, these challenges may be alleviated through use of qualitative measures of influence: if the role of human interference is 'dominant' for all identified vulnerabilities, then some problems may be solved by using that term. But for cases when precision is preferred or required, differences may become quite important. At this stage of event attribution research, it is poorly understood under which circumstances the differences can arise. Addressing these challenges might seem intractable and beyond the remit of climate change research. But if they are not tackled, then there is a risk of neglecting the most vulnerable in a vulnerability-centred research area, and of framing the questions to suit the answers.

Dáithí A. Stone (iD ${ }^{\bowtie}$, Suzanne M. Rosier and David J. Frame (iD) 2

${ }^{1}$ NIWA, Wellington, New Zealand. ${ }^{2}$ Victoria 
University of Wellington, Wellington, New Zealand.

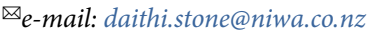

Published online: 25 March 2021

https://doi.org/10.1038/s41558-021-01012-x

References

1. Allen, M. Nature 421, 891-892 (2003).

2. Stott, P. A., Stone, D. A. \& Allen, M. R. Nature 432, 610-614 (2004).

3. National Academies of Sciences, Engineering and Medicine. Attribution of Extreme Weather Events in the Context of Climate Change (The National Academies Press, 2016).

4. Angélil, O. et al. Clim. Dyn. 50, 2739-2752 (2018).

5. Uhe, P. et al. Geophys. Res. Lett. 43, 8685-8693 (2016).

6. Angélil, O. et al. J. Climate 30, 5-16 (2017).

7. Wehner, M. et al. Weather Clim. Extremes 20, 1-8 (2018).

8. Hauser, M. et al. Earth's Future 5, 1034-1043 (2017).

9. Kim, Y.-H. et al. Weather Clim. Extremes 20, 33-44 (2018).

10. Otto, F. E. L. et al. Climatic Change 132, 531-543 (2015).

11. Harrington, L. J. Climatic Change 141, 641-654 (2017).

12. Dole, R. et al. Geophys. Res. Lett. 38, L06702 (2011).
13. Rahmstorf, S. \& Coumou, D. Proc. Natl Acad. Sci. USA 108 17905-17909 (2011)

14. Otto, F. E. L., Massey, N., van Oldenborgh, G. J., Jones, R. \& Allen, M. R. Geophys. Res. Lett. 39, L04702 (2012).

15. Shepherd, T. G. Curr. Clim. Change Rep. 2, 28-38 (2016).

16. Stott, P. A. et al. WIREs Clim. Change 7, 23-41 (2016).

17. Otto, F. E. L., van Oldenborgh, G. J., Eden, J., Stott, P. A., Karoly,

D. J. \& Allen, M. R. Nat. Clim. Change 6, 813-816 (2016).

18. Trenberth, K. E. Climatic Change 115, 283-290 (2012).

19. Trenberth, K. E., Fasullo, J. T. \& Shepherd, T. G. Nat. Clim. Change 5, 725-730 (2015).

20. Cramer, W. et al. in IPCC Climate Change 2014: Impacts, Adaptation, and Vulnerability (eds Field, C. B. et al.) 979-1037 (Cambridge Univ. Press, 2014).

21. Huggel, C., Stone, D., Eicken, H. \& Hansen, G. Climatic Change 133, 453-467 (2015)

22. Otto, F. E. L. et al. Bull. Amer. Meteor. Soc. 96, S35-S40 (2015).

23. Ebi, K. L., Ogden, N. H., Semenza, J. C. \& Woodward, A. Environ. Health Persp. 125, 085004 (2017)

24. Stone, D. et al. Climatic Change 121, 381-395 (2013).

25. Mitchell, D. et al. Environ. Res. Lett. 11, 074006 (2016).

26. Hannart, A. et al. Climatic Change 136, 155-174 (2016).

27. Haustein, K. et al. Environ. Res. Lett. 11, 064006 (2016).

28. Hoerling, M. et al. J. Clim. 26, 2811-2832 (2013).
29. Christidis, N., Stott, P. A. \& Zwiers, F. W. Clim. Dyn. 45, 1547-1564 (2015).

30. Lawal, K. et al. Predictability and Attribution of the South African Seasonal Climate (Water Research Commission, South Africa, 2015).

31. Stott, P. A. et al. in Climate Science for Serving Society: Research, Modelling and Prediction Priorities (eds Asrar, G. R. \& Hurrell, J. W.) 307-337 (Springer, 2013).

32. Jézéquel, A. et al. Climatic Change 149, 367-383 (2018).

33. Oppenheimer, M. et al. in Climate Change 2014: Impacts, Adaptation, and Vulnerability (eds Field, C. B. et al.) 1039-1099 (Cambridge Univ. Press, 2014).

Acknowledgements

This work was supported by the Ministry of

Business, Innovation and Employment of Aotearoa New Zealand through the Smart Ideas and Endeavour programmes.

Competing interests

The authors declare no competing interests. 